\title{
Etiology and prognosis of acute respiratory failure in patients with primary malignant brain tumors admitted to the intensive care unit
}

\author{
Maxens Decavèle ${ }^{1,2}\left(\right.$ ) Isabelle Rivals ${ }^{1,3} \cdot$ Clémence Marois $^{2} \cdot$ Marie Cantier $^{2} \cdot$ Nicolas Weiss $^{4} \cdot$ Léa Lemasle $^{2}$. \\ Hélène Prodanovic ${ }^{2} \cdot$ Khe Hoang-Xuan $^{5} \cdot$ Ahmed Idbaih $^{5} \cdot$ Thomas Similowski $^{1,2} \cdot$ Alexandre Demoule $^{1,2}$
}

Received: 8 October 2018 / Accepted: 5 December 2018 / Published online: 7 December 2018

(c) Springer Science+Business Media, LLC, part of Springer Nature 2018

\begin{abstract}
Purpose Acute respiratory failure (ARF) is common and potentially fatal in patients with primary malignant brain tumors (PMBT). However, few data are available regarding its precipitating factors and prognosis. We sought to: (1) compare the causes of ARF and the outcome between patients with PMBT and patients with other peripheral solid tumors (PST), (2) identify the factors influencing ICU survival in PMBT patients.

Methods Two-center retrospective case-control study from March 1996 to May 2014. Primary central nervous system lymphomas were also included.

Results Eighty-four patients with PMBT and 133 patients with PST were included. Acute infectious pneumonia was more frequent in PMBT than PST patients (77 vs. $36 \%$, p < 0.001). Pulmonary embolism was also more frequent in PMBT patients $(13 \%$ vs. $5 \%, \mathrm{p}=0.042)$, while cardiogenic pulmonary edema and acute-on-chronic respiratory failure were more frequent in PST patients (37 vs. $10 \%, \mathrm{p}<0.001$ ). Among acute infectious pneumonia, Pneumocystis pneumonia and aspiration pneumonia were more frequent in PMBT patients (19 vs. $2 \%, \mathrm{p}<0.001$ and 19 vs. $8 \%, \mathrm{p}<0.001$, respectively). ICU mortality was similar between PMBT and PST patients $(24 \%$ vs. $24 \%, \mathrm{p}=0.966)$. In multivariate analysis, cancer progression $(\mathrm{OR} 7.25$ 95\% CI 1.13-46.45, p=0.034), need for intubation (OR 7.01 95\% CI 1.29-38.54, $\mathrm{p}=0.022$ ), were independently associated with ICU mortality in PMBT patients.

Conclusions The cause of ARF in patients with PMBT differs significantly than those with PST and up to 50\% may have been prevented. Mortality did not differ between the two groups. These results suggest that PMBT alone is not a relevant criterion for ICU recusal.
\end{abstract}

Keywords Malignant brain tumors · Prognosis - Intensive care unit · Acute respiratory failure $\cdot$ Pneumocystis pneumonia . Critical care

Previous presentation: Preliminary results were presented at the most recent congress of the French Intensive Care Society, Paris, 2018.

Electronic supplementary material The online version of this article (https://doi.org/10.1007/s11060-018-03074-y) contains supplementary material, which is available to authorized users.

Maxens Decavèle

maxencesar@hotmail.fr

Extended author information available on the last page of the article

\section{Introduction}

Acute respiratory failure (ARF) is the main cause for intensive care unit (ICU) admission of cancer patients [1,2]. In these patients, acute infectious pneumonia is the leading cause of ARF, ranging from scarce infiltrates to lifethreatening acute respiratory distress syndrome [3]. While abundant data are available on the etiological spectrum [4] and prognosis of ARF among patients with hematologic malignancies [2] or other solid tumors [1], very little is known about patients with primary malignant brain tumors (PMBT).

In two recent reports describing the diagnosis and prognosis of PMBT patients admitted to the ICU [5, 6], ARF 
represented $16 \%$ and $45 \%$ of the reasons for admission, respectively, but the causes of ARF were not extensively described. Many findings suggest that the precipitating factors of ARF may differ between PMBT patients and those with other solid tumors. Firstly, PMBT patients are more severely immunocompromised than patients with other solid tumors as a result of both higher doses and more prolonged steroid therapy in addition to adjuvant radiotherapy and chemotherapy [6]. These factors are likely to contribute to the pathogenesis of opportunistic infections such as Pneumocystis jirovecii pneumonia (PCP) [7]. Secondly, as PMBT patients have fewer comorbidities [6], they are less likely to experience exacerbations of underlying cardiac or respiratory disease. Finally, at some time during the clinical course, PMBT are responsible for swallowing disorders [8, 9], subsequently predisposing to aspiration pneumonia.

As it has been clearly demonstrated that early identification of the cause of ARF is associated with better outcome in immunocompromised patients [2, 10], a better knowledge of the etiologic spectrum of ARF in PMBT patients is important. In addition, clear identification of the factors associated with the survival of these patients could improve the quality of triage and management decisions.

We hypothesized that the causes of ARF in PMBT patients differ significantly from the causes encountered in patients with other solid tumors and that factors associated with the prognosis of ARF in PMBT could be identified. To address these issues, we conducted the present case-control study to (1) compare the causes of ARF between PMBT patients and patients with other solid tumors, particularly focusing on PCP and (2) assess the factors associated with ICU mortality in PMBT patients.

\section{Patients and methods}

\section{Study design and settings}

The study was conducted from March 1996 to May 2014 in two medical ICUs: a 16-bed ICU in a pulmonology department (about 1,100 admissions per year) and a 16-bed ICU in a neurology department (about 300 admissions per year). Both ICUs are located in a 1600-bed university hospital with a strong neurological orientation including a specific neurooncology department (about 500 newly diagnosed patients each year) and the national reference center for high-grade oligodendroglial tumor (i.e. POLA Network) and primary central nervous system lymphoma (i.e. LOC Network). According to the French Public Health Code (L.1121-1 paragraph 1 and R1121-2,), informed consent is unnecessary for anonymous extraction and analysis of data from patients' medical charts. The study was approved by the Institutional
Review Board of the French Intensive Care Society. Data from this cohort have been previously published [6].

\section{Patient selection}

Data were extracted from the ICU database (FusionF, Varimed, France). This prospectively managed database comprehensively describes all ICU stays. The database of the two ICUs comprised 12,890 records, corresponding to $100 \%$ of admissions over the study period. For both cases and controls, when the same patient presented several ICU admissions, only the first stay was included in the analysis.

\section{PMBT selection (cases)}

This set of 12,890 records was retrospectively searched for all cases of PMBT according to the 2016 World Health Organization (WHO) Classification of Tumors of the Central Nervous System [11]. Patients with primary central nervous system lymphomas were also included. Patients with brain metastases from solid cancers, secondary central nervous system lymphoma, benign brain tumor and patients with another cause of immunodeficiency than cancer (i.e. organ transplantation, human immunodeficiency virus infection and/or associated hematologic malignancies) were excluded, as these conditions may directly influence the etiology of ARF. Patients who had recently undergone a neurosurgical operation $(<2$ weeks) or any other recent surgery ( $<4$ weeks) were also excluded.

Patients included in the study were those admitted to the ICU for ARF, defined as follows: (1) in spontaneously breathing patients (either standard oxygen or high-flow nasal cannula), ARF was defined by a respiratory rate $>20$ breaths $/ \mathrm{min}$ with $\mathrm{PaO}_{2} / \mathrm{FiO}_{2}<300 \mathrm{mmHg}$, (2) in mechanically ventilated patients (either noninvasive or invasive ventilation), $\mathrm{ARF}$ was defined by $\mathrm{PaO}_{2} / \mathrm{FiO}_{2}<300 \mathrm{mmHg}$ regardless of respiratory rate.

\section{Selection of controls with peripheral solid tumor (PST)}

The same set of 12,890 records was retrospectively searched for all cases of "solid malignant tumor" other than PMBT. This control group was called the "peripheral solid tumor (PST)" group. To ensure that the two groups were as comparable as possible in terms of factors that potentially influence the causes and prognosis of ARF, patients with metastatic solid tumors, patients with tumors in complete remission for more than 5 years, patients with hematologic malignancies, recent postoperative patients $(<4$ weeks) and patients with other types of immunodeficiency or chronic ventilator dependency were excluded. PST patients admitted to ICU for ARF, defined according to the same criteria as in PMBT patients, were included in this control group. 


\section{Definitions and data collection}

Tumour type was determined by histological examination and, in the PMBT group, by a highly suggestive clinical and radiological presentation when the tumor was not accessible to biopsy or surgery [12]. Grade I/II and Grade III/ IV gliomas were considered as low-grade and high-grade gliomas respectively. Cancer disease status was classified as newly diagnosed (when the tumor was diagnosed after ICU admission), in progression, controlled (partial response, complete response or stable disease) or unknown in the absence of reliable information. Performance status (PS) during the week preceding ICU admission according to the Eastern Cooperative Oncology Group Scale [13] and the charlson comorbidity index (CCI) [14] were collected for each patient. Physiological variables, such as body temperature, respiratory rate, heart rate, systolic blood pressure and glasgow coma scale (GCS), were recorded. Arterial blood gases, lymphocyte count and leukopenia (defined by leukocyte count $<1,500 / \mathrm{mm}^{3}$ ) were also recorded. Severity on admission was assessed by the simplified acute physiology score (SAPS) II [15] and the sequential organ failure assessment (SOFA) [16]. Three experienced critical care and respiratory physicians (A.D, H.P and M.D) determined the precipitating factor of ARF based on a set of clinical, laboratory, radiological and microbiological features. Microbial agents responsible for infectious pneumonia were also reported when identified. The diagnosis of PCP was based on high clinical suspicion and a microscopic visualization of Pneumocystis jirovecii cysts or trophozoites in bronchoalveolar lavage. Advanced life support measures taken during the ICU stay were recorded in PMBT patients. The ICU and hospital mortality were determined in all patients.

\section{Statistical analysis}

Continuous variables are expressed as median (interquartile range) and categorical variables are expressed as number (percentage). Between-group comparisons were performed using Mann-Whitney test (continuous variables) and Chi square test or Fisher's exact test as appropriate (categorical variables). Potential changes in mortality rates over the study period were analyzed using a Mann-Whitney test. Potential changes of severity over time were analyzed by Spearman's correlation.

Multivariate logistic regression was used to identify factors associated with ICU mortality in PMBT patients. Each potential risk factor for ICU mortality was first evaluated in univariate analysis. Factors yielding $\mathrm{p}$ values $\leq 0.20$ were entered in the logistic regression, except for SAPS II and SOFA, which were redundant with other variables. Continuous variables were not dichotomized. Missing data were imputed by the nearest neighbor method (1.1\%). The final model was determined using a backward stepwise logistic regression. All tests were two-tailed and $\mathrm{p}$ values $<0.05$ were considered statistically significant. The Hosmer-Lemeshow Chi square test was used to check the goodness-of-fit of the final model. Odds ratios (ORs) and their 95\% confidence intervals were calculated for significant factors. Analyses were performed using Matlab ${ }^{\mathrm{TM}}$ (Natick, MA, USA) version 9.3.0.713579 (R2017b) and its Statistics and Machine Learning Toolbox version 11.2.

\section{Results}

Figure 1 displays the study flow chart for both cases and controls. A total of 84 patients with PMBT were included. Tumor type was confirmed histologically in $74(88 \%)$ patients and was based on a strong clinical and radiological suspicion for the remaining ten patients and was distributed as follows: 18 (22\%) primary central nervous system lymphomas, 35 (42\%) high-grade gliomas, 27 (32\%) low-grade gliomas and 4 (4\%) other tumors (see also Table S1 in the Online Supplement). These PMBT patients were compared to 133 PST patients, distributed as follows: 27 (20\%) breast, 21 (16\%) lung, 17 (13\%) prostate, 14 (11\%) larynx, pharynx and oral cavity, $14(11 \%)$ urinary tract, $10(7 \%)$ colorectal, 8 (6\%) stomach, 7 (5\%) thyroid, 5 (4\%) liver, 4 (3\%) pancreas and $6(4 \%)$ other cancers ( 2 uterus, 2 ovary 1 melanoma and 1 gallbladder).

\section{Comparison of the causes of ARF between PMBT and PST patients}

Table 1 describes the main characteristics of PMBT and PST patients.

Acute infectious pneumonia was more frequent in PMBT patients, while acute cardiogenic pulmonary edema and acute-on-chronic respiratory failure were more frequent in PST patients (Fig. 2). The prevalence of pulmonary embolism as the primary cause of ARF was similar between the two groups. Of note, pulmonary embolism was observed in two PMBT patients and one PST patient, in whom the precipitating factor of ARF was pneumonia, resulting in an overall prevalence of pulmonary embolism of $13 \%(\mathrm{n}=11)$ in PMBT patients and 5\% $(\mathrm{n}=7)$ in PST patients $(\mathrm{p}=0.042)$. Among the other causes of ARF, upper airway obstruction by tumor and hemoptysis were exclusively observed in PST patients (see Table S2 in the Online Supplement).

Among the various forms of acute infectious pneumonia, PCP and aspiration pneumonia were more frequent in PMBT patients than in PST patients (Fig. 3). Similar proportions of documented or undocumented bacterial pneumonia, viral pneumonia and Aspergillus pneumonia were observed between the two groups (see also Table S2 in the Online 


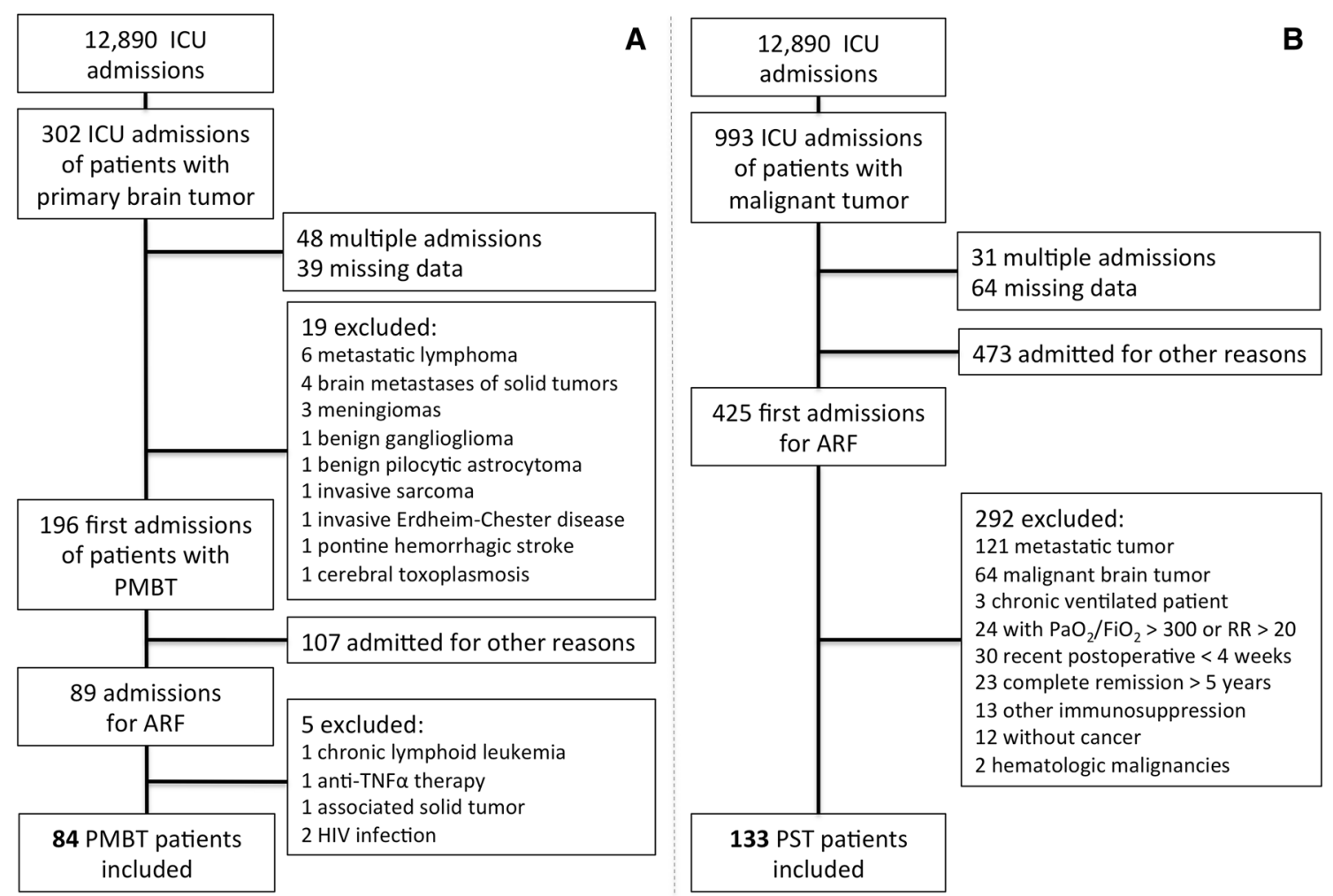

Fig. 1 Study flow chart of primary malignant brain tumor (PMBT, panel A) and peripheral solid tumor (PST, panel B) patients. ICU intensive care unit; $A R F$ acute respiratory failure; $T N F \alpha$ tumor necrosis factor alpha; $H I V$ human immunodeficiency virus; $R R$ respiratory rate

Supplement). The microbial agents documented in cases of acute infectious pneumonia are shown in Table S3 in the Online Supplement.

PMBT patients with PCP had a lower blood lymphocyte count than those with other causes of ARF (335 [170-666]/ $\mathrm{mm}^{3}$ vs. $\left.608[325-1000] / \mathrm{mm}^{3}, \mathrm{p}=0.017\right)$. None of the patients with a diagnosis of PCP had received prophylaxis prior to admission. The date of admission did not influence the incidence of PCP $(\mathrm{p}=0.950)$, aspiration pneumonia $(p=0.992)$ or pulmonary embolism $(p=0.601)$.

\section{Prognosis of PMBT patients}

ICU mortality, hospital mortality and SAPS II in PMBT patients did not vary according to the date of admission $(p=0.447, p=0.451$ and $p=0.543$, respectively).

Table 2 shows the factors associated with ICU mortality identified by univariate analysis. ICU mortality rates was similar in patients with primary central nervous system lymphoma, high-grade glioma, low-grade glioma and other tumors $(p=0.856)$. Multivariate logistic regression analysis showed that four variables were significantly associated with higher ICU mortality: cancer progression (OR 7.25, 95\% CI 1.14-46.46, $\mathrm{p}=0.033$ ), need for MV (OR 7.06 95\% CI $1.29-38.54, \mathrm{p}=0.022)$, respiratory rate (OR $1.1795 \%$
CI $1.05-1.30, \mathrm{p}=0.003)$ and heart rate (OR $1.0395 \% \mathrm{CI}$ $1.00-1.06, \mathrm{p}=0.034)$.

\section{Discussion}

The main results of this study can be summarized as follows: (1) infectious pneumonia is the leading cause of ARF in PMBT patients admitted to the ICU, while cardiogenic pulmonary edema and acute-on-chronic respiratory failure are less frequent in PMBT patients than in PST patients, (2) PCP and aspiration pneumonia are observed more frequently in PMBT patients than in patients with other solid tumors, (3) ICU and hospital mortalities are not significantly different between PMBT and PST patients, (4) cancer progression, heart rate, respiratory rate and initiation of mechanical ventilation were independently associated with ICU mortality in PMBT patients. To our knowledge, this is the largest cohort of PMBT patients admitted to the ICU for ARF and the first study to focus on the etiologic spectrum of ARF.

As previously reported in critically ill cancer patients, we observed a high prevalence of acute infectious pneumonia in our patient population [1-4]. These results could be explained by the frequent use of high-dose corticosteroids in PMBT patients (84\% in our study) [17]. In addition, in 
Table 1 Patient characteristics

\begin{tabular}{|c|c|c|c|}
\hline Variables & $\begin{array}{l}\text { PMBT patients } \\
\mathrm{n}=84\end{array}$ & $\begin{array}{l}\text { PST patients } \\
\mathrm{n}=133\end{array}$ & $p$ \\
\hline \multicolumn{4}{|l|}{ General characteristics } \\
\hline Age, years & $58[50-66]$ & $72[62-78]$ & $<0.001$ \\
\hline Gender (male), $n(\%)$ & $62(74)$ & $79(59)$ & 0.030 \\
\hline Chronic respiratory disease, $n(\%)$ & $10(12)$ & $49(37)$ & $<0.001$ \\
\hline Chronic heart failure, $n(\%)$ & $6(7)$ & $44(33)$ & $<0.001$ \\
\hline Corticosteroid therapy, $n(\%)$ & $69(84)$ & $4(3)$ & $<0.001$ \\
\hline Performance status $3-4, n(\%)$ & $59(70)$ & $39(41)$ & $<0.001$ \\
\hline \multicolumn{4}{|l|}{ On admission } \\
\hline SAPS II & $46[32-59]$ & 39 [29-53] & 0.534 \\
\hline Respiratory rate, breaths/min & $30[24-35]$ & $27[23-33]$ & 0.472 \\
\hline $\mathrm{PaO}_{2} / \mathrm{FiO}_{2}, m m H g$ & $161[101-233]$ & $166[120-232]$ & 0.113 \\
\hline Leukocytes count, $/ \mathrm{mm}^{3}$ & $8100[4200-$ & $10,300[7872-$ & 0.009 \\
\hline Leukopenia, $n(\%)$ & $\begin{array}{l}12,330] \\
9(11)\end{array}$ & $\begin{array}{l}15,600] \\
6(5)\end{array}$ & 0.079 \\
\hline \multicolumn{4}{|l|}{ Outcomes } \\
\hline Invasive mechanical ventilation, $n(\%)$ & $33(39)$ & $53(40)$ & 0.978 \\
\hline Noninvasive ventilation only, $n(\%)$ & $14(17)$ & $25(19)$ & 0.691 \\
\hline ICU mortality, $n(\%)$ & $20(24)$ & $32(24)$ & 0.966 \\
\hline Hospital mortality, $n(\%)$ & $39(46)$ & $65(49)$ & 0.687 \\
\hline ICU length of stay, days & $6[4-10]$ & $6[4-10]$ & 0.985 \\
\hline $\begin{array}{l}\text { Outcomes in the subgroup of invasively } \\
\text { mechanically ventilated patients }\end{array}$ & $\mathrm{n}=33$ & $\mathrm{n}=53$ & \\
\hline ICU mortality, $n(\%)$ & $14(42)$ & $26(49)$ & 0.548 \\
\hline Hospital mortality, $n(\%)$ & $24(73)$ & $38(72)$ & 0.917 \\
\hline
\end{tabular}

Continuous variables are expressed as median [interquartile range] and categorical data are expressed as number $(\%)$

PMBT, primary malignant brain tumor; PST, peripheral solid tumor (non-PMBT localized solid malignant tumor); SAPS II, Simplified Acute Physiology Score II; SOFA, Sequential Organ Failure Assessment

patients with primary central nervous system lymphomas, high-dose combination chemotherapy also exposes patients to an increased risk of neutropenia $[18,19]$ and subsequent infection.

The high incidence of PCP observed in this series has been previously reported in PMBT patients [7, 20, 21], but has not been specifically determined among patients with ARF. Moreover these reports on PCP are old and regards to chemotherapy and immunodeficiency profiles changes along these last two decades, the PCP incidence needed to be revisited. In contrast with patients with other solid tumors, patients with PMBT are exposed to high-dose corticosteroids, a well-known risk factor for PCP [22]. In addition to corticosteroids, the following factors may also contribute to cell-mediated immunosuppression in PMBT patients: brain radiotherapy [23], temozolomide [24, 25], and methotrexate [26]. All of these factors can also cause lymphopenia, which was more severe in PMBT patients.

Aspiration pneumonia was also more frequent in PMBT patients in the present study. Dysphagia or swallowing dysfunction is common in PMBT patients and represents a major cause of mortality in this population [27, 28]. Dysphagia is generally described in posterior fossa tumors and is related to impairment of anatomic structures extending from the brainstem nuclei to the laryngeal muscles, but can also occur in a context of supratentorial lesions or altered state of consciousness independently of the site of the tumor [29].

Acute cardiogenic pulmonary edema and acute-onchronic respiratory failure were observed less frequently in PMBT patients than in PST patients. This difference was probably related to the younger age of PMBT patients, the lower prevalence of comorbidities in this population $[6,30]$, and possibly also the limited cardiotoxicity of chemotherapeutic agents used in PMBT.

Finally, pulmonary embolism was observed more frequently in PMBT patients, which is also consistent with previous studies showing that PMBT are associated with one of the highest rates of venous thromboembolism in cancer patients [31], as high as $20 \%$ [32]. The main proposed explanations for the high prevalence of venous thromboembolism are the procoagulant state induced by glioblastoma 
Fig. 2 Causes of ARF in PMBT and PST patients. PMBT, primary malignant brain tumor; PST, peripheral solid tumor (non-PMBT localized solid malignant tumor); Acute/ chronic, acute-on-chronic. Proportions in each category are expressed in relation to the total sample size of PMBT $(n=84)$ and PST $(n=133)$ patients, respectively. The symbol * denotes a significant difference $(\mathrm{p}<0.05)$ between the two groups

Fig. 3 Causes of acute infectious pneumonia in PMBT and PST patients. PMBT, primary malignant brain tumor; PST, peripheral solid tumor (other than PMBT). Proportions in each category are expressed in relation to the total sample size of PMBT $(n=84)$ and PST $(\mathrm{n}=133)$ patients, respectively. The symbol $*$ denotes a significant difference $(\mathrm{p}<0.05)$ between the two groups
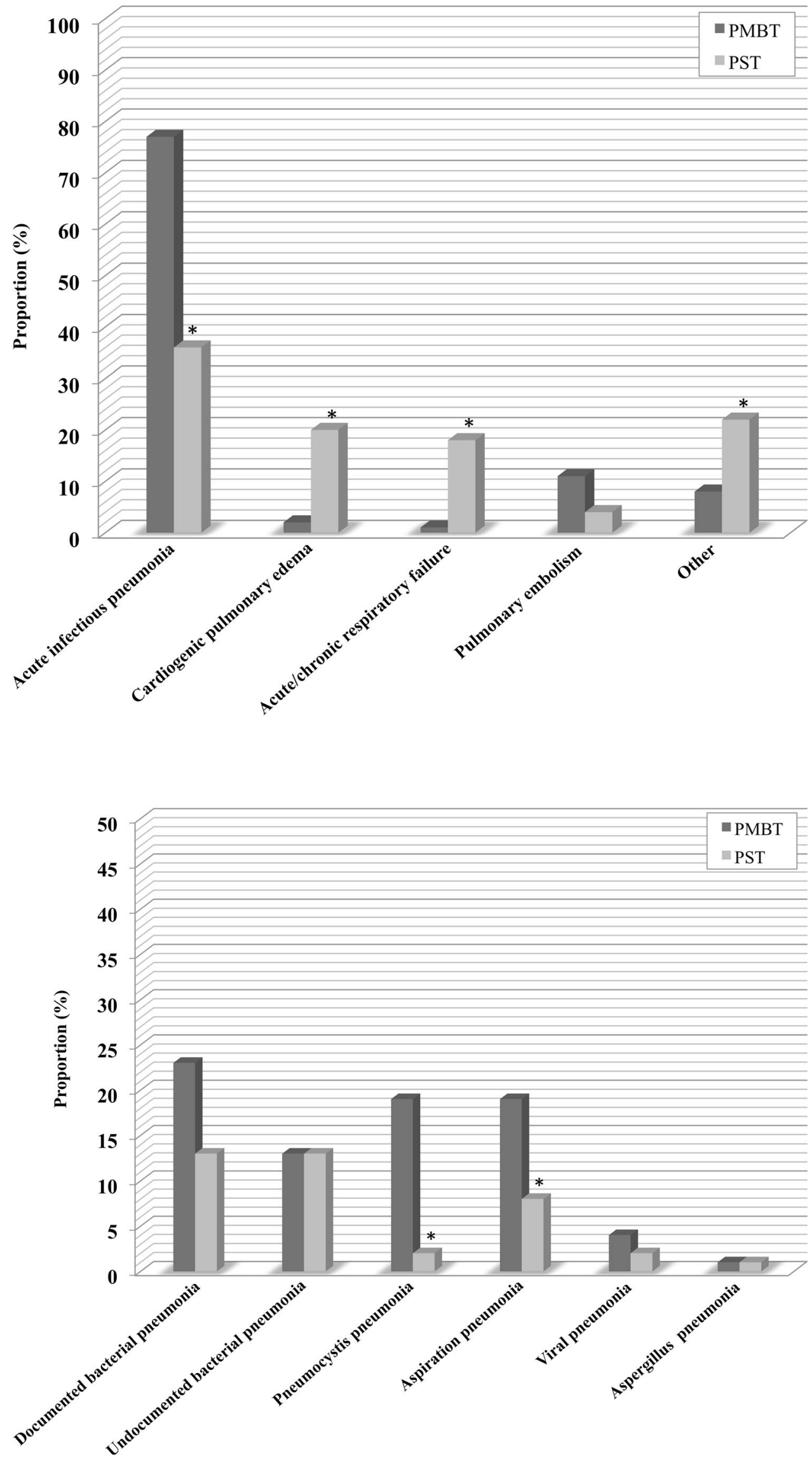
Table 2 Univariate analysis: factors associated with ICU mortality in patients with primary malignant brain tumor

\begin{tabular}{|c|c|c|c|}
\hline \multirow[t]{2}{*}{ Variables } & \multicolumn{2}{|l|}{ ICU Mortality } & \multirow[t]{2}{*}{$p$-value } \\
\hline & $\begin{array}{l}\text { Survivors } \\
\mathrm{n}=64\end{array}$ & $\begin{array}{l}\text { Non survivors } \\
\mathrm{n}=20\end{array}$ & \\
\hline \multicolumn{4}{|l|}{ General characteristics } \\
\hline Age, years & 59 [49-65] & $57[50-66]$ & 0.897 \\
\hline Gender (male), $n(\%)$ & $49(68)$ & $13(65)$ & 0.712 \\
\hline Performance Status 3-4, $n(\%)$ & $43(67)$ & $16(80)$ & 0.274 \\
\hline Charlson Comorbidity Index & $2[2-3]$ & $3[2-4]$ & 0.483 \\
\hline Corticosteroid therapy, $n(\%)$ & $52(81)$ & $17(85)$ & 0.534 \\
\hline Cancer progression & $7(11)$ & $6(30)$ & 0.039 \\
\hline \multicolumn{4}{|l|}{ Cause of acute respiratory failure } \\
\hline Acute infectious pneumonia, $n(\%)$ & $51(80)$ & $14(70)$ & 0.366 \\
\hline Pulmonary embolism, $n(\%)$ & $7(11)$ & $2(10)$ & 1.000 \\
\hline Cardiogenic pulmonary edema, $n(\%)$ & $1(2)$ & $1(5)$ & 0.372 \\
\hline Acute-on-chronic respiratory failure, $n(\%)$ & $1(2)$ & $0(0)$ & 0.423 \\
\hline Other, $n(\%)$ & $5(7)$ & $2(10)$ & 0.297 \\
\hline \multicolumn{4}{|l|}{ Tumor type } \\
\hline Primary CNS Lymphoma, $n(\%)$ & $15(23)$ & $3(15)$ & 0.422 \\
\hline High-grade glioma, $n(\%)$ & $26(41)$ & $11(55)$ & 0.258 \\
\hline Low-grade glioma $n(\%)$ & $19(30)$ & $6(30)$ & 0.979 \\
\hline Other, $n(\%)$ & $4(6)$ & $0(0)$ & 0.252 \\
\hline \multicolumn{4}{|l|}{ Severity scores } \\
\hline SAPS II & $41[28-54]$ & $62[46-71]$ & $<0.001$ \\
\hline SOFA & $4[2-7]$ & $8[5-10]$ & $<0.001$ \\
\hline \multicolumn{4}{|l|}{ Physiological variables on ICU admission } \\
\hline Respiratory rate, breaths/min & 29 [23-35] & $32[29-40]$ & 0.029 \\
\hline Heart rate, $b p m$ & $101[89-120]$ & $126[116-137]$ & 0.001 \\
\hline Glasgow coma scale & $14[11-15]$ & $8[5-13]$ & 0.004 \\
\hline \multicolumn{4}{|l|}{ Laboratory variables on ICU admission } \\
\hline Leukocyte count, $/ \mathrm{mm}^{3}$ & $7300[4040-12,115]$ & $8765[4705-12,173]$ & 0.325 \\
\hline Leukopenia, $n(\%)$ & $6(9)$ & $3(15)$ & 0.477 \\
\hline $\mathrm{pH}$ & $7.44[7.41-7.48]$ & 7.37 [7.18-7.44] & 0.011 \\
\hline $\mathrm{PaO}_{2} / \mathrm{FiO}_{2}, m m H g$ & $177[107-242]$ & $111[89-174]$ & 0.017 \\
\hline \multicolumn{4}{|l|}{ Life-support interventions } \\
\hline Mechanical ventilation, $n(\%)$ & $31(48)$ & $16(80)$ & $<0.001$ \\
\hline Vasopressor, $n(\%)$ & $11(17)$ & $11(55)$ & $<0.001$ \\
\hline Renal replacement therapy, $n(\%)$ & $0(0)$ & $2(10)$ & 0.014 \\
\hline
\end{tabular}

Continuous variables are expressed as median [interquartile range] and categorical data are expressed as number $(\%)$

ICU, intensive care unit; CNS, central nervous system; SAPS II, Simplified Acute Physiology Score II; SOFA, Sequential Organ Failure Assessment
[33], limited postoperative mobility, motor deficits, steroid-induced myopathy and the use of bevacizumab [34] in gliomas.

A major finding of this study was that the cause of ARF in PMBT patients could have been prevented in many cases. Pneumocystis pneumonia can be efficiently prevented by chemoprophylaxis [35], but none of the PMBT patients with a diagnosis of PCP received prophylactic chemotherapy. Of note, PCP prophylaxis in PMBT is not clearly recommended by guidelines after the initial phase of treatment [36, 37], despite the use of high-dose steroids in these patients. Pulmonary embolism can also be prevented by prophylactic anticoagulation [38]. Finally, swallowing disorders and their consequences (aspiration pneumonia) can also be prevented, although less effectively, by gastrostomy or enteral tube feeding, as in stroke patients [39], or by expiratory muscle training [40]. The epidemiologic knowledge gained from this study could 
pave the way for future trials evaluating combined preventive strategies aiming at reducing the incidence of ARF in PMBT patients.

Another important finding, is the absence of any significant difference in mortality different between cases PMBT and PST patients, which is consistent with the findings of recent studies, showing that mortality is not higher in PMBT patients than in patients with other solid tumors admitted to the ICU $[5,6]$. This is an important finding in terms of triage decisions, as it suggests that a diagnosis of PMBT alone should not preclude ICU admission of patients with ARF. However, as previously described in PMBT patients $[5,6]$ and in patients with other malignancies [1-4], initiation of mechanical ventilation and cancer progression are strongly associated with poor outcome.

This study has several limitations. First, the retrospective design implies a potential data collection bias. However, it would not be feasible to conduct prospective studies in this field due to the rarity of this disease. Of note, data were extracted from a prospectively managed database, which ensures a certain degree of reliability. Second, because PMBT are localized tumors, they were compared to nonmetastatic solid tumors, which creates a selection bias. For instance, patients with lung and pleural metastases, known to predispose to ARF, were excluded. Finally, a matching procedure was not performed on variables likely to influence the causes of ARF (e.g. cardiovascular and respiratory comorbidities, corticosteroids), due to the many differences between PMBT and PST patients regarding such variables, which would limit matching. However, although SAPS II, SOFA and $\mathrm{PaO}_{2} / \mathrm{FiO}_{2}$ could certainly influence the mortality, all these three variables were similar in the two groups.

In conclusion, ARF in PMBT patients is due to a wide range of causes, different from those generally observed in other cancer patients. The high prevalence of preventable causes suggests the need for guidelines to help physicians institute prophylactic measures in these patients. Finally, the prognosis of ARF in PMBT patients does not appear to differ from that of patients with other solid tumors, and the identification of simple prognostic factors may help physicians to optimize triage decisions.

Acknowledgements We thank Anthony Saul for his help with English style and grammar

Author Contributions MD: methodology, data curation, conceptualization, validation, writing - original draft, and writing - review and editing. NW: data curation, conceptualization, validation, writing - original draft. CM: data curation, validation. LL: validation, software. MC: data curation, validation, $\mathrm{KH}-\mathrm{X}$ : validation. HP: data curation, conceptualization, validation, IR: methodology, software, validation, writing - original draft. AI: supervision, validation, AD: methodology, data curation, supervision, conceptualization, validation, writing - original draft, and writing - review and editing, TS: supervision, validation, conceptualization, writing - original draft.

\section{Compliance with ethical standards}

Conflict of interest Alexandre Demoule has signed research contracts with Covidien, Maquet, Philips and Ait Liquide Santé; he has also received personal fees from Covidien, Maquet and MSD. Ahmed Idbaih reports research funding from $\mathrm{La}$ Fondation ARC pour la recherche sur le Cancer, Carthera, Beta-Innov, and Intselchimos; travel funding from Hoffmann-La Roche; and personal fees from Novartis, La Lettre du Cancérologue, BMS, and Cipla unrelated to the submitted work. Nicolas Weiss has signed research contracts with Eumedica, BMS, MedDay pharmaceuticals; he has also received personal fees from Norgine and Alpha-Wasserman. Thomas Similowski has received grant research from Coviden, Philips, Pierre Fabre Médicaments, Air Liquide Medical Systems; he has also received personal fees from Takeda, Teva Pharma, Lungpacer Inc, Almirall France, Pierre Fabre Médicaments, Novartis, Mundipharma, Invacare, Astra Zeneca, Boehringer Ingelheim and GlaxoSmithKline. Hélène Prodanovic, Khê HoangXuan, Clémence Marois, Isabelle Rivals, Marie Cantier, Léa Lemasle and Maxens Decavèle all declare that they have no conflict of interest.

Research involving human participants and/or animals and informed consent. According to the French Public Health Code (L.1121-1 paragraph 1 and R1121-2,), informed consent is unnecessary for anonymous extraction and analysis of data from patients' medical charts. The study was approved by the Institutional Review Board of the French Intensive Care Society.

\section{References}

1. Azoulay E, Thiéry G, Chevret S et al (2004) The prognosis of acute respiratory failure in critically ill cancer patients. Medicine (Baltimore) 83:360-370

2. Azoulay E, Mokart D, Pène F, Schlemmer B, Chevret S, Lemiale V (2013) Outcomes of critically ill patients with hematologic malignancies: prospective multicenter data from France and Belgium--a groupe de recherche respiratoire en réanimation oncohématologique study. J Clin Oncol 31:2810-2818

3. Azoulay E, Lemiale V, Mokart D et al (2014) Acute respiratory distress syndrome in patients with malignancies. Intensive Care Med 40:1106-1114

4. Azoulay E, Schlemmer B (2006) Diagnostic strategy in cancer patients with acute respiratory failure. Intensive Care Med 32:808-822

5. Tabouret E, Boucard C, Devillier R, Barrie M, Boussen S, Autran D, Chinot O, Bruder N (2016) Neuro-oncological patients admitted in intensive-care unit: predictive factors and functional outcome. J Neurooncol 127:111-117

6. Decavèle M, Weiss N, Rivals I et al (2017) Prognosis of patients with primary malignant brain tumors admitted to the intensive care unit: a two-decade experience. J Neurol 264:2303-2312

7. Mahindra AK, Grossman SA (2003) Pneumocystis carinii pneumonia in HIV negative patients with primary brain tumors. J Neurooncol 63:263-270

8. Wesling M, Brady S, Jensen M, Nickell M, Statkus D, Escobar N (2013) Dysphagia outcomes in patients with brain tumors undergoing inpatient rehabilitation. Dysphagia 18:203-210

9. Lee WH, Oh BM, Seo HG et al (2016) One-year outcome of postoperative swallowing impairment in pediatric patients with posterior fossa brain tumor. J Neurooncol 127:73-81

10. Mokart D, Lambert J, Schnell D et al (2013) Delayed intensive care unit admission is associated with increased mortality in patients with cancer with acute respiratory failure. Leuk Lymphoma 54:1724-1729 
11. Louis DN, Perry A, Reifenberger G et al (2016) The 2016 World Health Organization classification of tumors of the central nervous system: a summary. Acta Neuropathol 131:803-820

12. Vaquero J, Martínez R, Manrique M (2000) Stereotactic biopsy for brain tumors: is it always necessary? Surg Neurol 53:432-437

13. Oken MM, Creech RH, Tormey DC et al (1982) Toxicity and response criteria of the Eastern Cooperative Oncology Group. Am J Clin Oncol 5:649-655

14. Charlson M, Szatrowski TP, Peterson J, Gold J (1994) Validation of a combined comorbidity index. J Clin Epidemiol 47:1245-1251

15. Le Gall JR, Lemeshow S, Saulnier FA (1993) New simplified acute physiology score (SAPS II) based on a European/North American multicenter study. JAMA 270:2957-2963

16. Vincent JL, Moreno R, Takala J et al (1996) The SOFA (sepsisrelated organ failure assessment) score to describe organ dysfunction/failure. On behalf of the working group on sepsis-related problems of the European Society of intensive care medicine. Intensive Care Med 22:707-710

17. Gea-Banacloche JC, Opal SM, Jorgensen J, Carcillo JA, Sepkowitz KA, Cordonnier C (2004) Sepsis associated with immunosuppressive medications: an evidence-based review. Crit Care Med 32:S578-S590

18. Ferreri AJ, Reni M, Foppoli M et al (2009) High-dose cytarabine plus high-dose methotrexate versus high-dose methotrexate alone in patients with primary CNS lymphoma: a randomised phase 2 trial. Lancet 374:1512-1520

19. Wolach O, Bairey O, Lahav M (2010) Late-onset neutropenia after rituximab treatment: case series and comprehensive review of the literature. Medicine (Baltimore) 2010 89:308-318

20. Schiff D (1996) Pneumocystis pneumonia in brain tumor patients: risk factors and clinical features. J Neurooncol 27:235-240

21. Henson JW, Jalaj JK, Walker RW, Stover DE, Fels AO (1991) Pneumocystis carinii pneumonia in patients with primary brain tumors. Arch Neurol 48:406-409

22. Yale SH, Limper AH (1996) Pneumocystis carinii pneumonia in patients without acquired immunodeficiency syndrome: associated illness and prior corticosteroid therapy. Mayo Clin Proc 71:5-13

23. Hughes MA, Parisi M, Grossman S, Kleinberg L (2005) Primary brain tumors treated with steroids and radiotherapy: low CD4 counts and risk of infection. Int J Radiat Oncol Biol Phys 62:1423-1426

24. Sengupta S, Marrinan J, Frishman C, Sampath P (2012) Impact of temozolomide on immune response during malignant glioma chemotherapy. Clin Dev Immunol 2012:831090

25. Lin AJ, Campian JL, Hui C et al (2018) Impact of concurrent versus adjuvant chemotherapy on the severity and duration of lymphopenia in glioma patients treated with radiation therapy. $\mathrm{J}$ Neurooncol 136:403-411
26. Leff RL, Mckenzie R (1990) Rheumatoid arthritis, methotrexate therapy and Pneumocystis pneumonia. Ann Intern Med 112:116

27. Park DH, Chun MH, Lee SJ, Song YB (2013) Comparison of swallowing functions between brain tumor and stroke patients. Ann Rehabil Med 37:633-641

28. Wadhwa R, Toms J, Chittiboina P et al (2014) Dysphagia following posterior fossa surgery in adults. World Neurosurg 82:822-827

29. Lind CD (2003) Dysphagia evaluation and treatment. Gastroenterol Clin N Am 32:553-575

30. Wrensch M, Minn Y, Chew T et al (2002) Epidemiology of primary brain tumors: current concepts and review of the literature. Neuro Oncol 4:278-299

31. Petterson TM, Marks RS, Ashrani AA et al (2015) Risk of sitespecific cancer in incident venous thromboembolism: a population-based study. Thromb Res 135:472-478

32. Semrad TJ, O'Donnell R, Wun T et al (2007) Epidemiology of venous thromboembolism in 9489 patients with malignant glioma. J Neurosurg 106:601-608

33. Sartori MT, Della Puppa A, Ballin A et al (2011) Prothrombotic state in glioblastoma multiforme: an evaluation of the procoagulant activity of circulating microparticles. J Neurooncol 104:225-231

34. Nalluri SR, Chu D, Keresztes R et al (2008) Risk of venous thromboembolism with the angiogenesis inhibitor bevacizumab in cancer patients: a meta-analysis. JAMA 300:2277-2285

35. Green H, Paul M, Vidal L, Leibovici L (2007) Prophylaxis of pneumocystis pneumonia in immunocompromised non-HIVinfected patients: systematic review and meta-analysis of randomized controlled trials. Mayo Clin Proc 82:1052-1059

36. Stupp R, Brada M, van den Bent MJ, Tonn JC, Pentheroudakis G, ESMO Guidelines Working Group.(2014) High-grade glioma ESMO Clinical Practice Guidelines for diagnosis, treatment and follow-up. Ann Oncol 25:93-101

37. Hoang-Xuan K, Bessell E, Bromberg J et al (2015) European association for Neuro-Oncology task force on primary CNS lymphoma. Diagnosis and treatment of primary CNS lymphoma in immunocompetent patients: guidelines from the European association for Neuro-Oncology. Lancet Oncol 16:e322-e332

38. Lyman GH, Bohlke K, Khorana AA et al (2015) Venous thromboembolism prophylaxis and treatment in patients with cancer: american society of clinical oncology clinical practice guideline Update 2014. J Clin Oncol 33:654-656

39. Dennis MS, Lewis SC, Warlow C (2005) FOOD Trial Collaboration: Effect of timing and method of enteral tube feeding for dysphagic stroke patients (FOOD): a multicentre randomised controlled trial. Lancet 365:764-772

40. Troche MS, Okun MS, Rosenbek JC et al (2010) Aspiration and swallowing in Parkinson disease and rehabilitation with EMST: a randomized trial. Neurology 75:1912-1919

\section{Affiliations}

\section{Maxens Decavèle ${ }^{1,2}$ - Isabelle Rivals ${ }^{1,3} \cdot$ Clémence Marois $^{2} \cdot$ Marie Cantier $^{2} \cdot$ Nicolas Weiss $^{4} \cdot$ Léa Lemasle $^{2}$.

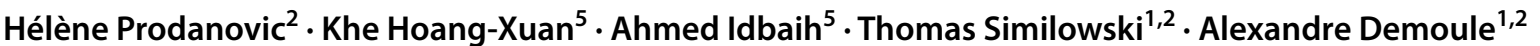

1 Sorbonne Universités, UPMC Univ Paris 06, INSERM, UMRS_1158 Neurophysiologie respiratoire expérimentale et clinique, Paris, France

2 AP-HP, Groupe Hospitalier Pitié-Salpêtrière Charles Foix, Service de Pneumologie et Réanimation Médicale (Département “R3S”), F-75013 Paris, France
3 Equipe de Statistique Appliquée, ESPCI Paris, PSL Research University, UMRS 1158 Neurophysiologie Respiratoire Expérimentale et Clinique, Paris, France

4 Sorbonne Université, Brain Liver Pitié-Salpêtrière (BLIPS) Study Group, INSERM UMR_S 938, Centre de Recherche Saint-Antoine, Assistance Publique - Hôpitaux de Paris, Groupement Hospitalier Pitié-Salpêtrière Charles 
Foix, Département de Neurologie, Unité de réanimation neurologique, Paris, France

5 Sorbonne Université, Inserm, CNRS, UMR S 1127, Institut du Cerveau et de la Moelle épinière, ICM, AP-HP, Hôpitaux
Universitaires La Pitié Salpêtrière - Charles Foix, Service de Neurologie 2-Mazarin, 75013 Paris, France 